\title{
EL PROGRAMA PISA APLICAT A ALUMNES UNIVERSITARIS DE L'ENSENYAMENT DE MESTRES. RESULTATS D'UNA EXPERIÈNCIA
}

\author{
Luisa Girondo Pérez. Àrea de Didàctica de la Matemàtica. URV. \\ Agustí Salvat Altés. Àrea de Didàctica de les Ciències Experimentals. URV
}

\section{Introducció}

La vida en una societat altament tecnificada i complexa com l'actual exigeix dels ciutadans unes determinades destreses i habilitats per poder-s'hi inserir i progressar. L'adquisició de moltes d'aquestes destreses i habilitats s'inicia en el període d'escolarització primària, i cada vegada més, els sistemes educatius dels diferents països van agafant responsabilitat en l'ajuda al desenvolupament intel.lectual dels escolars.

Una de les àrees curriculars amb major potencial de contribució en l'ajuda d'aquest desenvolupament és l'àrea de matemàtiques, la qual aporta les primeres nocions, mètodes i símbols que més tard donaran lloc al pensament científic. Constatem, doncs, que és important en la formació inicial de mestres portar a terme els controls adequats que ens permetin organitzar la formació d'acord amb les necessitats professionals futures, considerant en un primer lloc les mancances actuals. En aquest marc els autors d'aquest treball ens vàrem plantejar el fet de contrastar la competència matemàtica dels estudiants de Magisteri, en les especialitats que capaciten per treballar com a mestres en l'etapa entre els 6 i 12 anys, amb la competència general desitjable per a qualsevol ciutadà. Aquesta competència general l'hem obtingut del conegut informe PISA de l'OCDE (Organización para la Cooperación y Desarrollo Económico) i que es descriu a la primera part d'aquest article. A la segona part s'analitzen els resultats obtinguts a l'aplicar als futurs mestres els ítems triats en comparació amb els resultats publicats pel PISA.

\section{Característiques del programa PISA}

L'OCDE és un organisme que té per objectiu bàsic "promoure polítiques destinades a assolir un creixement sostenible de l'economia i l'ocupació, mantenint l'estabilitat financera amb la finalitat de contribuir a l'economia mundial". Atès que la forma en la qual els sistemes educatius preparen els seus estudiants perquè desenvolupin el paper de ciutadans actius és una dada impor- tant sobre l'evolució d'una societat, l'educació i la formació són àrees prioritàries per a l'OCDE. És en aquest sentit que els països de l'OCDE tenen un especial interès a conèixer en quina mesura els joves que acaben l'escolaritat obligatòria estan preparats per als reptes de la societat del segle XXI. El Programa Nacional de Evaluación de Alumnos -PISA- (Program for International Student Assesment) és el destinat a estudiar el rendiment d'aquests escolars quan acaben l'educació obligatòria.

Fa uns 10 anys l'OCDE va establir un seguit d'indicadors educatius que es consideraven importants per expressar el desenvolupament d'una societat. Indicadors que pretenien mostrar la qualitat dels sistemes educatius mitjançant les anomenades "competències" que assoleixen els escolars en determinades disciplines bàsiques, que comprenen els dominis de la lectura comprensiva i l'alfabetització matemàtica i científica. Aquests indicadors caracteritzen i mostren la preparació dels estudiants de 15 anys per desenvolupar un paper actiu com a ciutadans reflexius i participatius.

El programa, que permet generar indicadors dels objectius assolits en educació, es porta a terme mitjançant una avaluació internacional. Avaluació que és la de major abast realitzada fins al moment. La informació prové dels resultats obtinguts en proves de llapis i paper fetes pels alumnes de 15 anys. Les proves són comunes a tots els països, segueixen procediments d'aplicació que també són comuns, i es porten a terme mitjançant avaluadors externs. L'avaluació se centra a conèixer com els estudiants poden utilitzar el que han après, en situacions habituals de la vida quotidiana i no solament -ni principalment- a saber quins coneixements del currículum han après.

Cada 3 anys es realitza un estudi per obtenir les dades amb les quals s'elaboren els indicadors. A cada avaluació s'avaluen les tres àrees (lectura comprensiva, alfabetització matemàtica i alfabetització científica), però l'èmfasi es posa més en una d'elles. Al 2003 li tocà a la matemàtica. 


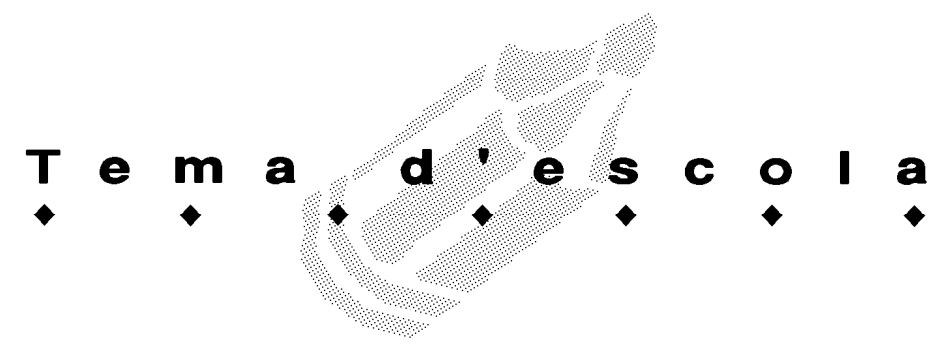

A l'estudi PISA 2003 hi han intervingut entre $5000 \mathrm{i}$ 10000 estudiants de cadascun dels 42 països participants. A cada país hi han intervingut, almenys, 150 centres educatius diferents. A Espanya, d'un total de 418005 estudiants de 15 anys escolaritzats, l'estudi n'ha analitzat 10791 , pertanyents a 383 centres educatius diferents (OCDE, 2005 b). Catalunya hi ha participat amb una mostra àmplia, la qual cosa va permetre tenir resultats independents, a més de participar en les mitjanes espanyoles.

\section{L'alfabetització o competència matemàtica}

El domini sobre la matemàtica que ha analitzat el PISA 2003 es denomina alfabetització matemàtica (Mathematical Literacy) i també, de forma general, "competència matemàtica". La competència matemàtica es considera una part important de la preparació educativa i, per tant, l'avaluació de les competències matemàtiques és un dels eixos principals del programa PISA. L'alfabetització matemàtica fa referència a les capacitats dels estudiants per analitzar, raonar i comunicar eficaçment quan enuncien, formulen i resolen problemes matemàtics en una diversitat de situacions i dominis. El terme "alfabetització" s'ha elegit per subratllar que el mateix coneixement matemàtic i les seves destreses -tal i com es defineixen al currículum tradicional de les matemàtiquesno constitueixen el focus d'atenció principal del projecte PISA, ans al contrari: es fa èmfasi en el coneixement matemàtic que es posa en joc en una infinitat de contextos diferents, fent servir procediments reflexius, variats $\mathrm{i}$ basats en la intuïció personal. És a dir, en les competències i capacitats personals.

Reduir el concepte d'alfabetització als aspectes de caire més funcional resulta excessivament simple. A l'estudi PISA es contempla un significat més ampli; és un significat de tipus comprensiu: ha de mostrar la capacitat matemàtica dels estudiants per enfrontar-se als problemes quotidians més variats. Es podria dir que la descripció d'un ciutadà matemàticament il.lustrat és la d'aquell que "és capaç de pensar fent servir idees matemàtiques". En les relacions dels ciutadans amb el món social i natural, així com en la seva vida habitual, els ciutadans s'enfronten a situacions diverses quan planifiquen, fan pressupostos, compren, viatgen, s'alimenten, cuinen, gestionen les seves finances personals, fan estimacions, analitzen qüestions polítiques i prenen moltes decisions en les quals fan servir el raonament quantitatiu, l'espacial o altres nocions matemàtiques que ajuden a clarificar, formular i resoldre problemes. En aquesta línia, l'estudi PISA/OCDE entén per alfabetització matemàtica: "la capacitat individual per identificar i entendre el paper que les matemàtiques tenen al món, fer judicis ben fonamentats i fer servir les matemàtiques en aquells moments en què es presentin necessitats en la vida de cada individu com a ciutadà constructiu, compromès i reflexiu" (OCDE, 2003). "Usar les matemàtiques, implicar-se en elles" significa, a més d'utilitzar i resoldre problemes matemàtics, "comunicar-se, relacionar-se amb..., valorar, apreciar les matemàtiques i gaudir-ne".

\section{Els instruments d'avaluació}

Els responsables de l'estudi PISA reconeixen la dificultat d'avaluar l'alfabetització matemàtica dels estudiants de 15 anys mitjançant una simple prova escrita de llapis i paper, ja que el procés complet d'actuació des de la realitat a la matemàtica $i$ tornada a la realitat sovint implica un treball en col-laboració en la cerca de recursos, la qual cosa requereix un temps considerable. Aquesta limitació fa que l'estudi PISA hagi preparat un conjunt d'ítems que avaluïn diferents parts d'aquest complex procés. L'estratègia seguida per construir un banc d'ítems que, de manera equilibrada, cobreixin les fases de l'anomenat procés de matematització té en compte tres variables o dimensions: 1) el contingut matemàtic al qual fan referència els problemes o tasques proposades; 2) les situacions i contextos emprats com a font de materials i d'estímuls en els quals se situa el problema, i 3) les competències que cal activar per connectar el món real, d'on sorgeix el problema, amb les matemàtiques que cal utilitzar per resoldre'l.

\section{Contingut matemàtic}

Les idees, estructures i conceptes matemàtics s'han generat i constituït com a eines que serveixin per organitzar els fenòmens del món natural, social i mental. El currículum escolar de matemàtiques s'acostuma a organitzar mitjançant continguts temàtics com la geometria, l'àlgebra, funcions, etc., la qual cosa facilita el desenvolupament estructurat d'una assignatura. No obstant això, els fenòmens del món real que comporten un tractament matemàtic no estan organitzats així.

PISA caracteritza blocs contextuals on s'utilitzen les destreses i conceptes matemàtics; a aquests blocs els anomena "idees fonamentals". Aquestes dees -que satisfan les condicions de respectar el desenvolupament històric i contribuir a la reflexió principal del currículum escolar-, són:

- Quantitat. Aquesta categoria subratlla la necessitat de quantificar per organitzar el món. Inclou els fenòmens numèrics, conjuntament amb les relacions i patrons quantitatius. Un aspecte important és el raonament quantitatiu, que inclou el sentit numèric, la representació de nombres de formes diverses, les dimensions relatives, la com- 


\section{T e ma d e s c o l a}

prensió del significat de les operacions, l'aritmètica, el càlcul mental i l'estimació.

- Espai i forma. Les formes poden considerar-se com a patrons. Els patrons numèrics serveixen com a models relativament simples de molts tipus de fenòmens. L'estudi de les formes està relacionat amb el concepte d'espai proper, la qual cosa requereix la comprensió de les propietats dels objectes i de les seves posicions relatives. També significa entendre les relacions entre les formes i les seves representacions visuals. Els estudiants han d'aprendre a desenvolupar-se a través de l'espai, les formes i les construccions. També han d'entendre com els objectes tridimensionals es poden representar en dues dimensions, com s'interpreten les ombres i quines són les seves perspectives i funcions.

- Canvi i relacions. Cada fenomen natural és una manifestació del canvi. Al nostre entorn hi ha una multitud de relacions temporals i permanents entre fenòmens. Moltes d'aquestes relacions es poden modelar directament mitjançant funcions matemàtiques: lineals, exponencials, periòdiques, discretes o contínues. El pensament funcional, és a dir, pensar en termes "de" i "sobre" relacions, és una de les fites bàsiques de l'ensenyament de la matemàtica. Les relacions es poden representar mitjançant símbols, dibuixos geomètrics, taules i gràfics.

- Incertesa. Per incertesa s'entenen dos tòpics relacionats: el tractament de les dades i l'atzar. En altres paraules: la matèria d'estudi de l'estadística i la probabilitat. Els conceptes i activitats importants d'aquesta àrea són: la recollida de dades, l'anàlisi de les dades i la seva representació, la probabilitat i la inferència.

\section{Situacions i contextos}

Un aspecte important de l'alfabetització matemàtica consisteix a utilitzar i fer matemàtiques en una gran varietat de situacions i contextos. Als alumnes se'ls presenten una sèrie de textos diferents, al voltant dels quals es formulen una sèrie de preguntes. La segona variable que es considera als ítems de l'avaluació PISA és la situació, que contextualitza i dota de significat la tasca proposada. Les situacions que es tenen en compte són:

- Les situacions personals estan relacionades amb les activitats diàries dels alumnes. Fan referència a la

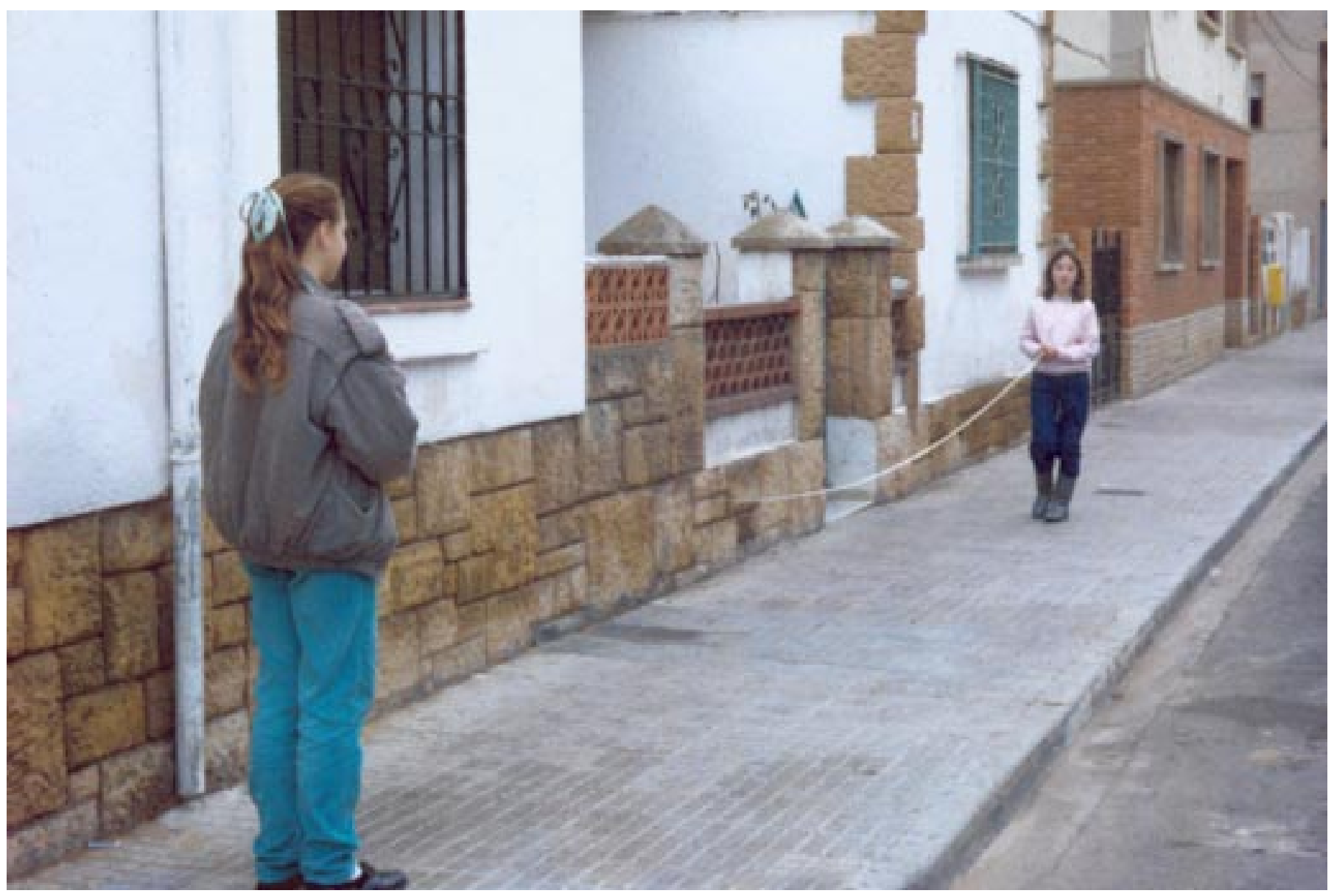




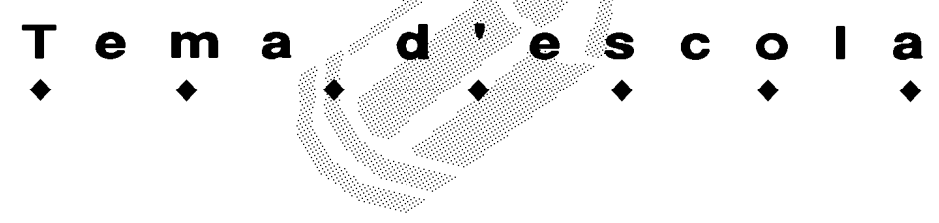

forma en la qual un problema matemàtic afecta immediatament l'individu i a la forma en la qual l'individu capta el context del problema.

- Les situacions educatives o laborals, l'alumne les troba en el mateix centre escolar o en un entorn de treball. Fan referència a la forma en la qual el centre escolar o el lloc de treball li proposen una tasca que implica una activitat matemàtica si vol trobar la resposta.

- Les situacions públiques fan referència a la comunitat local -o a una altra de més àmplia- de la qual els estudiants n'han d'observar un determinat aspecte que els obligui a activar la comprensió, coneixements i habilitats matemàtiques per tal d'avaluar una situació externa que tingui repercussions importants en la vida pública.

- Les situacions científiques són les més abstractes i poden implicar la comprensió d'un procés tecnològic, una interpretació teòrica o un problema específicament matemàtic.

\section{Tipus de competències i variables de procés}

La tercera variable fa referència a les competències que es volen mostrar, ja que se suposa que cada ítem activa unes determinades habilitats i capacitats matemàtiques dels alumnes.

En termes més precisos, el projecte també delimita unes competències específiques derivades directament del procés de matematització. PISA posa l'accent en allò que l'alumne és capaç de fer amb els seus coneixements i habilitats matemàtiques, i no en el domini formal dels conceptes i les habilitats. És a dir, on posa l'accent és en les capacitats, les habilitats i els procediments de l'alumne.

Les competències tracten de centrar l'educació en l'estudiant, en el seu aprenentatge i en el significat funcional del procés. Els tipus de competències seleccionades pel PISA són: 1) pensar i raonar; 2) argumentar; 3) comunicar; 4) modelar; 5) planificar i resoldre problemes; 6) representar, i 7) utilitzar el llenguatge simbòlic, formal i tècnic i les operacions.

Cadascuna de les competències enunciades admet diferents nivells d'aprofundiment; les tasques proposades

$\begin{array}{cl}\text { Pregunta } & \text { Títol } \\ 1 & \text { Caminant-1 } \\ 2 & \text { Caminant-2 } \\ 9 & \text { Fer un xat-1 } \\ 10 & \text { Fer un xat-2 } \\ 36 & \text { Suport al president } \\ 37 & \text { El millor cotxe-1 } \\ 39 & \text { El millor cotxe-2 }\end{array}$

als estudiants plantegen diferents tipus de nivells i demandes cognitives. Els experts de l'estudi PISA consideren tres estadis de complexitat al considerar els ítems que s'empren per avaluar les competències:

- Primer estadi: Reproducció i procediments rutinaris. En aquest nivell s'engloben aquells exercicis que són relativament familiars i que només exigeixen la reiteració dels coneixements practicats. En definitiva, en les tasques d'aquest nivell no es necessita posar en joc els aspectes complexos de les competències implicades, ja que la resolució és possible actuant, només, a un nivell de coneixement familiar o rutinari.

- Segon estadi: Connexions $i$ integració per resoldre problemes estàndards. En aquest nivell s'hi posen aquelles tasques que permeten resoldre problemes que no són rutinaris, però que s'ubiquen en entorns familiars o propers.

- Tercer estadi: Reflexió (raonament, argumentació, intuïció i generalització per resoldre problemes originals). Aquest nivell de complexitat mobilitza competències que requereixen una certa comprensió i reflexió per part de l'alumne, i creativitat per identificar conceptes o enllaçar idees de procedència diversa. Les tasques d'aquest nivell impliquen l'ús d'alts nivells de complexitat en les competències posades en joc.

\section{Prova de matemàtiques amb els alumnes de $1 \mathrm{r}$ curs de l'ensenyament de Magisteri}

L'interès per l'estudi PISA a Espanya s'ha posat de manifest mitjançant diversos treballs. A l'informe econòmic de l'OCDE sobre Espanya es proposen una sèrie de recomanacions i diagnòstics, entre els quals es diu: "Les proves de l'estudi PISA han posat de manifest la deficient qualitat de l'escolarització obligatòria" (OCDE, 2005 a). Aquesta afirmació és la que ha portat els autors d'aquest treball a intentar mesurar com evoluciona l'alfabetització matemàtica a mesura que augmenta la distància temporal amb l'acabament de I'ESO, perquè es pot suposar, d'entrada, que el nivell de competència matemàtica augmenta amb els anys d'escolaritat de l'alumne. És per això que dels

\section{Procés}

Reproducció
Connexions
Connexions
Reflexió
Connexions
Reproducció
Reflexió

$\begin{gathered}\text { Nivell de } \\ \text { dificultat }\end{gathered}$
5
6,5 i 4
3
5
5
2
5

$\begin{array}{lc}\text { Contingut } & \begin{array}{c}\text { Competència/ } \\ \text { Situació }\end{array} \\ \text { Canvi i relacions } & \text { Personal } \\ \text { Canvi i relacions } & \text { Personal } \\ \text { Canvi i relacions } & \text { Personal } \\ \text { Canvi i relacions } & \text { Personal } \\ \text { Incertesa } & \text { Pública } \\ \text { Canvi i relacions } & \text { Pública } \\ \text { Canvi i relacions } & \text { Pública }\end{array}$

Taula 0. Característiques de les tasques seleccionades perquè les resolguin els estudiants de $1 \mathrm{r}$ curs de l'ensenyament de Mestres. 


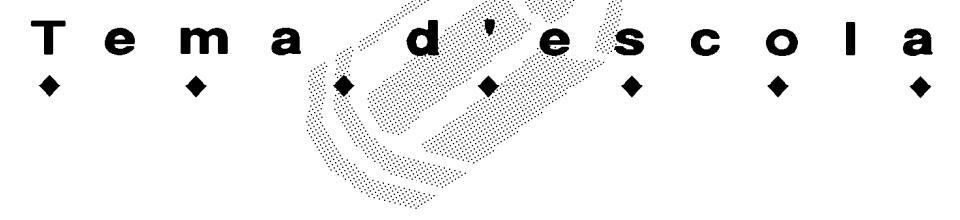

ítems alliberats a l'estudi PISA s'ha seleccionat una mostra de set tasques perquè les realitzin els alumnes universitaris de primer curs de l'ensenyament de Magisteri. Les tasques seleccionades es caracteritzen a la taula 0 .

\section{Descripció de la població estudiada}

La prova es va realitzar durant la primera quinzena del mes d'octubre del 2005, amb una durada aproximada d'una hora. A l'inici de la prova, es va avisar els alumnes que aquesta era anònima i que el fet de contestar-la no tindria cap mena de repercussió en la qualificació de l'assignatura.

El total d'alumnes que hi van intervenir ha estat de 132, distribuïts per especialitats així: Educació Física (EF, a partir d'ara), 39; Educació Primària (EP, a partir d'ara), 38; Educació Musical (EM, a partir d'ara), 29; i Llengües Estrangeres (LE, a partir d'ara), 26.

Pel que fa al sexe de la població enquestada, el total de 132 alumnes es distribueix de la següent manera: 104 (78,8\%) són del sexe femení i 26 (19,7\%) del masculí, mentre que 2 alumnes no van especificar de quin sexe eren. Per especialitats, la mostra es reparteix així: Educació Física (25 noies i 13 nois), Educació Musical (21 noies i 7 nois), Educació Primària (36 noies i 2 nois) i a Llengües Estrangeres (22 noies i 4 nois).

Referent a les edats dels alumnes, l'interval d'edats oscil.la entre els 17 i els 34 anys, però la majoria de la mostra $(66,6 \%)$ se situa entre els 18 i els 20 anys. La composició detallada d'edats de la població enquestada

\begin{tabular}{rrrrrrr} 
Edat & EF & EM & EP & \multicolumn{2}{c}{ LE } & \multicolumn{2}{c}{ TOTAL (\%) } \\
17 & 1 & 0 & 2 & 0 & 3 & $(2,3)$ \\
18 & 8 & 15 & 17 & 7 & 32 & $(35,6)$ \\
19 & 10 & 7 & 5 & 6 & 21 & $(21,2)$ \\
20 & 5 & 2 & 2 & 4 & 11 & $(9,8)$ \\
21 & 2 & 1 & 5 & 1 & 8 & $(6,8)$ \\
22 & 3 & 2 & 2 & 2 & 7 & $(6,8)$ \\
23 & 3 & 0 & 1 & 1 & 5 & $(3,8)$ \\
24 & 0 & 1 & 1 & 1 & 2 & $(2,3)$ \\
25 & 0 & 0 & 1 & 2 & 3 & $(2,3)$ \\
26 & 1 & 0 & 0 & 0 & 1 & $(0,8)$ \\
27 & 2 & 0 & 0 & 0 & 2 & $(1,5)$ \\
28 & 1 & 0 & 0 & 1 & 2 & $(1,5)$ \\
32 & 0 & 0 & 1 & 0 & 1 & $(0,8)$ \\
34 & 0 & 0 & 1 & 0 & 1 & $(0,8)$ \\
- & 3 & 1 & 0 & 1 & 4 & $(3,8)$
\end{tabular}

Taula 1. Distribució d'edats de la població enquestada segons l'especialitat cursada. El guió (-) a la columna "edat" significa que no l'han especificat. El total es dóna en freqüència absoluta i en percentage (entre parèntesis). es detalla a la taula 1.

La prova es va estructurar en 7 preguntes, que tot seguit s'expliciten i de les quals s'analitza la resposta obtinguda.

\section{Preguntes 1 i 2. Caminant}

La fotografia mostra les petjades d'un home caminant. La longitud del pas $P$ és la distància entre els extrems posteriors de dues petjades consecutives. Per als homes, la fórmula $n / P=140$, dóna una relació aproximada entre $n$ i $P$, on: $n=$ nombre de passes per minut, $i$ $P=$ longitud del pas, en metres.

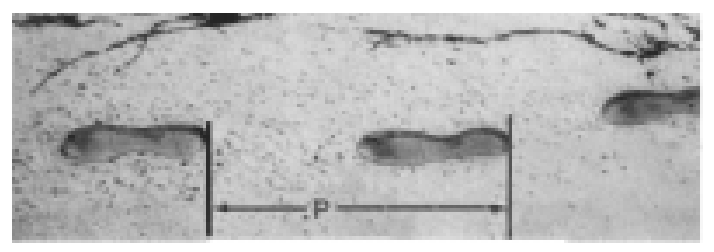

Pregunta 1. Si s'aplica la fórmula al caminar de l'Enric $i$ aquest fa 70 passos per minut, ¿quina és la longitud del pas de l'Enric? Explica com ho calcules.

Pregunta 2. En Bernat sap que les seves passes són de 0,80 metres. El caminar d'en Bernat també s'ajusta a la fórmula. Calcula la velocitat a la qual camina en Bernat en metres per minut i quilòmetres per hora. Explica com ho calcules.

Valoració de la Pregunta 1

La puntuació de la primera pregunta, així com la de la resta de preguntes, s'ha fet seguint els criteris d'avaluació descrits al document: PISA 2003. Pruebas de Matemáticas y de Solución de Problemas (INECSE, 2005). Aquesta puntuació per a la pregunta 1 és:

- Màxima puntuació (codi 2): 0,5 m, 50 cm, 1/2 (no cal especificar les unitats).

- Puntuació parcial (codi 1): Substitució correcta dels números a la fórmula, però amb resposta incorrecta o sense resposta, o bé la fórmula s'ha transformat correctament en $p=n / 140$, però el treball posterior és incorrecte.

- Cap puntuació:

Codi 0: Quan han donat altres respostes.

Codi 9: Sense resposta.

Els resultats obtinguts pels alumnes de les diferents especialitats de Magisteri (MAG, a partir d'ara) es mostren a la taula 2. A títol comparatiu també s'hi inclouen els resultats obtinguts pels estudiants de 15 anys dels països de l'OCDE, d'Espanya (ESP, a partir d'ara) i de Catalunya (CAT, a partir d'ara).

ANÀLISI DELS RESULTATS

Malgrat que el percentatge de respostes totalment correctes (codi 2$)$ és alt a EF (79,5\%) i EM (75,9\%), 


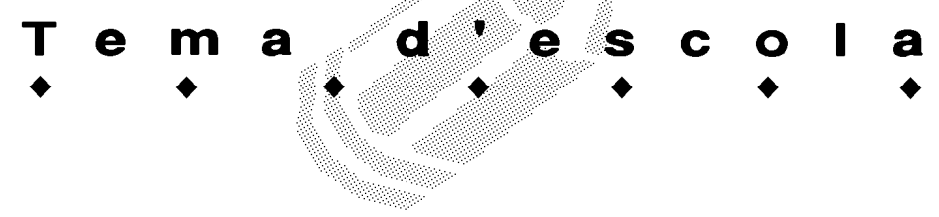

RESPOSTA PREGUNTA 1 (En \%)

Codi 2 Codi 1 Codi $2+1$ Codi 0 Codi 9

$\begin{array}{lccccl}\text { OCDE } & - & - & 36,3 & - & - \\ \text { ESP } & - & - & 38,4 & - & - \\ \text { CAT } & - & - & 33,9 & - & - \\ \text { EF } & \mathbf{7 9 , 5} & \mathbf{1 0 , 2} & \mathbf{8 9 , 7} & \mathbf{1 0 , 3} & \mathbf{0} \\ \text { EM } & \mathbf{7 5 , 9} & \mathbf{0} & \mathbf{7 5 , 9} & \mathbf{2 4 , 1} & \mathbf{0} \\ \text { EP } & \mathbf{5 7 , 9} & \mathbf{1 5 , 8} & \mathbf{7 3 , 7} & \mathbf{2 3 , 7} & \mathbf{2 , 6} \\ \text { LE } & \mathbf{5 0 , 0} & \mathbf{0} & \mathbf{5 0 , 0} & \mathbf{4 6 , 2} & \mathbf{3 , 8} \\ \text { MAG } & \mathbf{6 6 , 7} & \mathbf{7 , 6} & \mathbf{7 4 , 3} & \mathbf{2 4 , 2} & \mathbf{1 , 5}\end{array}$

Taula 2. Percentatge de resposta obtinguda a la pregunta 1 (Caminar). El guió (-) indica que no es disposa de dades numèriques per a aquest codi.

baixa de forma considerable a EP $(57 \%)$ i a LE $(50,0 \%)$. Per contra, el percentatge de respostes errònies (codi $0)$, és preocupant a EP $(23,7 \%)$ i inacceptable a LE $(46,1 \%)$, ja que aquesta tasca correspon al primer nivell de dificultat: Reproducció i procediments rutinaris.

Entre les respostes amb puntuació parcial (codi 1) i nul.la (codi 0 ), n'hi ha que destaquen força -no pel fet dels errors que han comès els alumnes en el traball posterior, un cop han substituït els corresponents números a la fórmula- sinó pel resultat absurd al qual han arribat. De respostes n'hi ha per a tots el gustos: alguns donen una longitud del pas de $20 \mathrm{~cm}$, altres 9800 metres, passant pels passos de $9,8 \mathrm{~m}$ i $4900 \mathrm{~m}$ !

També hi ha qui hi introdueix la idea de velocitat per calcular no se sap què ni com ("espai recorregut $=\mathrm{v} / \mathrm{t}=$ $70 / 1=70$ passos"); qui considera que la longitud del pas és una velocitat (" $n=140 \times 0,8=112 \mathrm{~m}$ per minut, $6^{\prime} 72$ $\mathrm{Km} / \mathrm{h}$ "); qui fa els càlculs a ull, encara que no sàpiga què és allò que està trobant ("14/20=70. Ha de ser baix: 14 passos"), i qui no en té ni idea de com fer-ho ("Dividim $p$ per la longitud del pas, en metres").

Valoració de la Pregunta 2

La puntuació, segons els criteris PISA, és:
Màxima puntuació: 3 punts.

- Codi 31: Respostes correctes per a $\mathrm{m} / \mathrm{min} \mathrm{i} \mathrm{km} / \mathrm{h}$ : (no cal especificar les unitats). Exemple: " $n=140 \times 0,90$ $=112$. Camina per minut: $112 \times 0,80$ metres $=89,6$ metres. La seva velocitat és de $89,6 \mathrm{~m} / \mathrm{min}$. Per tant, la seva velocitat és 5,38 o $5,4 \mathrm{~km} / \mathrm{h}$ ".

Són acceptables els errors deguts als arrodoniments. Per exemple, $90 \mathrm{~m} / \mathrm{min}$ i 5,3 km/h (89x60) són acceptables i cal donar la puntuació màxima.

Puntuació parcial: 2 punts.

- Codi 21: Com en el cas del codi 3, però es falla al multiplicar per 0,80 per convertir els passos per minut a metres per minut. Per exemple: "La velocitat és $112 \mathrm{~m} /$ $\min$ i $6,72 \mathrm{~km} / \mathrm{h}$ ".

- Codi 22: La velocitat en m/min és correcta $(89,6 \mathrm{~m} /$ $\mathrm{min}$ ) però la conversió a $\mathrm{km} / \mathrm{h}$ és incorrecta o no s'ha fet. Exemple: "89,6 m/min i 0,087 km/h".

- Codi 23: El mètode és correcte, però el resultat és incorrecte a causa de petits errors de càlcul (no inclosos en els codis $21 \mathrm{i} 22)$. Exemples:

" $\mathrm{n}=140 \times 0,8=1120 ; 1120 \times 0,9=896$. Camina 896 $\mathrm{m} / \mathrm{min} ; 53,76 \mathrm{~km} / \mathrm{h}$ ".

$" \mathrm{n}=140 \times 0,9=116 ; 116 \times 0,8=92,8.92,8 \mathrm{~m} / \mathrm{min}$-> $5,57 \mathrm{~km} / \mathrm{h}$ ".

- Codi 24: Només es dóna 5,4 km/h, però no $89,6 \mathrm{~m} /$ min (no es mostren els càlculs intermedis).

Puntuació parcial: 1 punt.

- Codi 11: " $n=140 \times 0,80=12$ ". No es mostra el treball posterior o bé és incorrecte a partir d'aquest punt. Exemples: " $\mathrm{n}=112 ; 0,112 \mathrm{~km} / \mathrm{h}$ ". " $\mathrm{n}=112 ; 1120 \mathrm{~km} / \mathrm{h}$ ". "112 m/ $\min , 504 \mathrm{~km} / \mathrm{h}$ ".

Cap puntuació: 0 punts.

- Codi 00: Quan s'han donat altres respostes.

- Codi 99: Sense resposta.

Els resultats obtinguts pels alumnes de les quatre especialitats de Magisteri (en percentatge) es mostren a la taula 3.

\begin{tabular}{|c|c|c|c|c|c|c|c|c|c|}
\hline & & & & RESPOS & A PREGL & NTA 2 (En \%) & & & \\
\hline & Codi 31 & Codi 21 & Codi 22 & Codi 23 & Codi 24 & $\begin{array}{c}\text { Codi } \\
21+22+23+24\end{array}$ & Codi 11 & Codi 00 & Codi 99 \\
\hline OCDE & 8,0 & - & - & - & - & 9,0 & 19,9 & - & - \\
\hline ESP & 7,5 & - & - & - & - & 8,3 & 23,7 & - & - \\
\hline CAT & 12,0 & - & - & - & - & 6,2 & 24,9 & - & - \\
\hline EF & 33,3 & 7,7 & 2,6 & 2,6 & 0 & 12,9 & 15,3 & 28,2 & 10,3 \\
\hline EM & 20,7 & 0 & 10,3 & 0 & 0 & 10,3 & 51,7 & 17,3 & 0 \\
\hline EP & 15,8 & 7,9 & 7,9 & 0 & 0 & 15,8 & 26,3 & 36,8 & 5,3 \\
\hline LE & 19,2 & 0 & 0 & 15,4 & 0 & 15,4 & 11,5 & 46,2 & 7,7 \\
\hline MAG & 22,0 & 4,5 & 5,3 & 3,8 & 0 & 13,6 & 24,0 & 31,8 & 8,6 \\
\hline
\end{tabular}

Taula 3. Percentatge de resposta obtinguda a la pregunta 2 (Caminar). El guió (-) indica que no es disposa de dades numèriques per a aquest codi. 


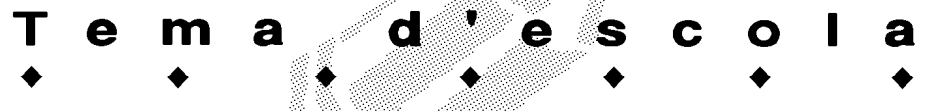

AnÀlisi dels Resultats

$\mathrm{Si}$ ens centrem en les respostes correctes (catalogades amb el codi 31 ), ens adonarem que els resultats són bastant pobres. A EP el percentatge de resposta correcta se situa en un minso 15,8\%. La situació a EM i LE no és gaire diferent $(19,2 \%$ i $20,7 \%$, respectivament). I a EF, on hi ha el valor més alt, només resolen bé la qüestió un de cada tres alumnes (33,3\%).

Pel que fa a les respostes catalogades amb els codis $21,22,23$ i 24 (es falla al multiplicar per 0,80 per convertir els passos per minut a $\mathrm{m} / \mathrm{min}$ o $\mathrm{km} / \mathrm{h}$; o es fan petits errors de càlcul), la situació és preocupant: cometen més errors d'aquesta mena els futurs mestres que no pas els alumnes de 15 anys! Però el greu de la qüestió no és que facin tants errors de càlcul. El greu rau en el fet que quan els errors de càlcul els porten a una solució absurda, ni se n'adonen! Com a mostra d'això que s'acaba de dir serveixen els següents exemples: "a $89,6 \mathrm{~m} / \mathrm{min}$ li fan correspondre $1,8 \mathrm{Km} / \mathrm{h}$ "; " $89,6 \mathrm{~m} / \mathrm{min}$ i 53,76 Km/h"; "112 m/min. i 1,86 Km/h.".

A les respostes etiquetades amb el codi 11 (quan es calcula bé la velocitat en passos/min, però els càlculs posteriors són incorrectes o no es mostren), la situació és semblant a l'anterior: a EM i EP es cometen més errors d'aquest tipus (51,7\% i $26,3 \%$, respectivament) que els que fan els alumnes de l'ESO (Catalunya: $24,9 \%$, Espanya: $23,7 \%$ i OCDE: 19,9\%). Alguns exemples d'aquestes equivocacions són: "112 x 0,80 dóna 39'60 quilòmetres per hora"; "112 pas $/ \mathrm{min}=1$ '86 pas/hora"; "112 passos $/$ minut = 0'534 Km/hora"; "112 pas $/ \mathrm{min}=80$ $\mathrm{Km} /$ hora" $\mathrm{i}$ "112 passos per minut $=6.720$ passos per $\mathrm{km} "$.

Pel que fa a les respostes errònies (cobertes pel codi 0 ), els resultats són excessivament alts a EF $(28,2 \%)$, EP $(36,8 \%)$ i LE $(46,2 \%)$. Alguns exemples d'aquests errors són: "n/0,80 =140 =12 passos x minut; 9'6 m x minut=0'6 Km/hora"; " $\mathrm{n}=140 \times 0$ 0' $80=112$ passos x minut; 0 ' $112 \mathrm{Km} / \mathrm{h}$."; " $175=140 / 0,8=140$ passos/minut" i " $0,80+140=14,80$ passos fa en Bernat".

\section{Preguntes 9 i 10. Fer un xat}

Mark (de Sydney, Austràlia) i Hans (de Berlín, Alemanya) es comuniquen sovint a través d'internet mitjançant el xat. Per poder fer el "xat" han de connectar-se a internet tots dos alhora. Per trobar una hora apropiada per al "xat", Mark va a buscar un mapa horari mundial $i$ va trobar la informació que es mostra a la figura 1.

Pregunta 9: Quan són les 7:00 de la tarda a Sydney, quina hora és a Berlín?

Pregunta 10: Mark i Hans no poden mantenir el "xat" entre les 9:00 del matí i les 4:30 de la tarda, de les seves respectives hores locals, perquè han d'anar al col.legi.

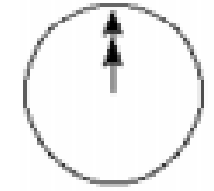

Greenwich 12 de la nit

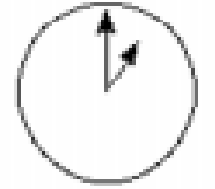

Berlín 1:00 de la nit

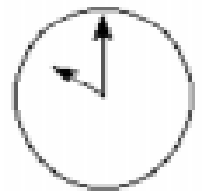

Sydney 10:00 del matí
Figura 1.

Tampoc no ho poden fer des de les 11:00 de la nit fins a les 7:00 de la matí de les seves respectives hores locals perquè estaran dormint.

A quines hores podrien fer el "xat" Mark i Hans? Escriu les respectives hores locals a la taula.

\begin{tabular}{|c|c|}
\hline Lloc & Hora \\
\hline Sydney & \\
\hline Berlín & \\
\hline
\end{tabular}

Valoració de la Pregunta 9

La puntuació donada pel programa PISA és màxima (codi 1) quan es contesta: "10 del matí o 10:00". La puntuació nul-la (codi 0) s'aplica quan es donen altres respostes o quan no és contestat (codi 9).

Els resultats obtinguts pels alumnes de Magisteri al realitzar la tasca de la pregunta 9 es mostren a la taula 4.

$\begin{array}{lccc} & \text { RESPOSTA PREGUNTA 9 (En \%) } \\ \text { OCDE } & \text { Codi } 1 & \text { Codi } 0 & \text { Codi } 9 \\ \text { ESP } & 53,7 & - & - \\ \text { CAT } & 46,0 & - & - \\ \text { EF } & 47,1 & - & - \\ \text { EM } & \mathbf{8 2 , 1} & 17,9 & 0 \\ \text { EP } & 75,9 & 20,7 & \mathbf{3 , 4} \\ \text { LE } & 65,8 & \mathbf{3 4 , 2} & \mathbf{0} \\ \text { MAG } & 61,5 & 38,5 & 0 \\ & 72,0 & 27,3 & 0,7\end{array}$

Taula 4. Percentatge de resposta obtinguda a la pregunta 9 (Fer un xat). El guió (-) indica que no es disposa de dades numèriques per a aquest codi.

\section{ANÀLISI DELS Resultats}

La baixa dificultat de la tasca a realitzar (nivell 3, "connexions") fa que el nombre de respostes correctes sigui elevat, excepte a EP i LE. A aquestes dues especialitats el nombre de respostes errònies és preocupant: $34,2 \%$ a EP i $38,6 \%$ a LE.

Valoració de la Pregunta 10

El criteri de puntuació indicat al PISA és:

Es qualifica amb la màxima puntuació (codi 1) quan s'escriu qualsevol hora o interval de temps que acom- 


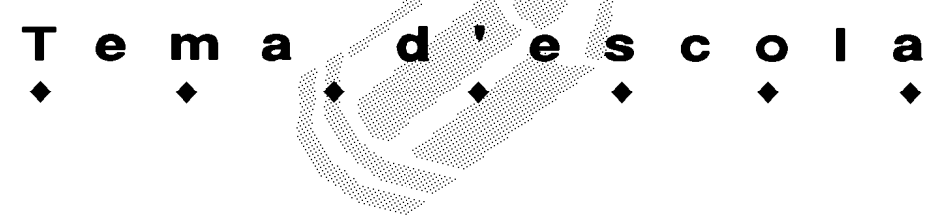

pleixi les 9 hores de diferència i que es trobi dins d'un d'aquests dos intervals: Sydney (4:30-6:00 de la tarda), Berlín (7:30-9:00 del matí) o bé: Sydney (7:00-8:00 del matí), Berlín (10:00-11:00 de la nit). Si es respon amb un interval, l'interval complet ha de satisfer els requisits. Si no s'especifica "matí" o "tarda", però les hores es consideren correctes, cal donar la resposta com a bona.

No es dóna cap puntuació quan es donen altres respostes, encara que una de les dues hores sigui correcta (codi 0), o quan no s'ha contestat (codi 9).

Els resultats obtinguts pels alumnes de Magisteri al realitzar la tasca de la pregunta 10 s'especifiquen a la taula 5.

\begin{tabular}{lccc}
\multicolumn{4}{c}{ RESPOSTA PREGUNTA 10 (En \%) } \\
OCDE & Codi 1 & Codi 0 & Codi 9 \\
ESP & 28,8 & - & - \\
CAT & 21,6 & - & - \\
EF & 22,4 & - & - \\
EM & $\mathbf{3 8 , 5}$ & $\mathbf{4 8 , 7}$ & $\mathbf{1 2 , 8}$ \\
EP & $\mathbf{1 7 , 2}$ & $\mathbf{6 9 , 0}$ & $\mathbf{1 3 , 8}$ \\
LE & $\mathbf{1 3 , 2}$ & $\mathbf{6 3 , 2}$ & $\mathbf{2 3 , 6}$ \\
MAG & $\mathbf{4 2 , 3}$ & $\mathbf{5 0 , 0}$ & $\mathbf{7 , 7}$ \\
MAG & $\mathbf{2 7 , 3}$ & $\mathbf{5 7 , 6}$ & $\mathbf{1 5 , 1}$
\end{tabular}

Taula 5. Percentatge de resposta obtinguda a la pregunta 10 (Fer un xat). El guió (-) indica que no es disposa de dades numèriques per a aquest codi.

AnÀlisi dels Resultats

Encara que aquesta tasca correspongui a un nivell de dificultat catalogat amb valor 5 , ja que implica l'ús - per part de l'alumne- d'alts nivells de complexitat en les competències que ha de posar en joc per resoldre la tasca, no és una pregunta tipificada amb el máxim valor de dificultat per les proves PISA. Malgrat això que s'acaba de dir, els resultats obtinguts pels futurs mestres són els més baixos de tota la prova. I fins i tot a dues especialitats són més baixos que els corresponents als alumnes de l'ESO: $13,2 \%$ a EP i $17,2 \%$ a EM enfront del $28,8 \%$ a I'OCDE; $21,6 \%$ a ESP i $22,4 \%$ a CAT.

A títol d'exemple es pot comentar que només un alumne (dels 132) ha estat capaç d'elaborar una estratègia de resolució congruent amb la complexitat de les competències que cal posar en joc en tasques d'aquest nivell de dificultat.

L'elevat nombre de respostes errònies resulta escandalós, ja que pràcticament totes les especialitats freguen o superen el $50 \%$ d'errors (a EM el percentatge es dispara fins al 69,0).

Pel que fa als que "no contesten" (codi 9), la mitjana aritmètica de Magisteri se situa en un $15,1 \%$, encara que a EP el valor puja fins al $23,6 \%$.

\section{Pregunta 36. Suport al president}

A Zedlàndia es van realitzar diversos sondeigs d'opinió per conèixer el nivell de suport al president a les properes eleccions. Quatre diaris van fer sondeigs per separat a tota la nació. Els resultats dels sondeigs dels quatre diaris es mostren a continuació:

Diari 1: 36,5\% de suport (sondeig realitzat el 6 de gener, amb una mostra de 500 ciutadans triats a l'atzar $i$ amb dret a vot).

Diari 2: 41,0\% de suport (sondeig realitzat el 20 de gener, amb una mostra de 500 ciutadans triats a l'atzar $i$ amb dret a vot).

Diari 3: 39,0\% de suport (sondeig realitzat el 20 de gener, amb una mostra de 1000 ciutadans triats a l'atzar $i$ amb dret a vot).

Diari 4: 44,5\% de suport (sondeig realitzat el 20 de gener, amb una mostra de 1000 lectors que van trucar per telèfon per votar).

Si les eleccions se celebren el 25 de gener, ¿quin dels resultats dels diaris és més probable que sigui la millor predicció del nivell de suport al president? (encercla el nom del diari). Dóna dues raons que justifiquin la teva resposta.

Valoració de la Pregunta 36

El criteri de puntuació indicat al PISA és:

S'ha de donar la màxima puntuació (codi 2), quan es contesta: "diari 3" i s'indica que "el sondeig és el més recent, amb una mostra més gran, amb una selecció de la mostra feta a l'atzar, i només es pregunta a les persones amb dret a vot" (s'han d'indicar, almenys, dues raons i s'ha d'ignorar qualsevol informació addicional, irrellevant o incorrecta).

No s'atorga cap puntuació (codi 0 ) quan es donen altres respostes, o quan no s'ha contestat (codi 9).

Els resultats obtinguts pels alumnes de Magisteri al realitzar la tasca de la pregunta 36 es comptabilitzen a la taula 6 .

\begin{tabular}{lccc}
\multicolumn{5}{c}{ RESPOSTA PREGUNTA 36 (En \%) } \\
OCDE & Codi 2 & Codi 0 & Codi 9 \\
ESP & 35,7 & - & - \\
CAT & 26,8 & - & - \\
EF & 30,6 & - & - \\
EM & 79,5 & $\mathbf{1 7 , 9}$ & $\mathbf{2 , 6}$ \\
EP & 62,1 & $\mathbf{3 4 , 5}$ & $\mathbf{3 , 4}$ \\
LE & 42,1 & $\mathbf{5 2 , 6}$ & $\mathbf{5 , 3}$ \\
MAG & $\mathbf{7 6 , 9}$ & $\mathbf{2 3 , 1}$ & $\mathbf{0}$ \\
& $\mathbf{6 4 , 4}$ & $\mathbf{3 2 , 6}$ & $\mathbf{3 , 0}$
\end{tabular}

Taula 6. Percentatge de resposta obtinguda a la pregunta 36 (Suport al president). El guió (-) indica que no es disposa de dades numèriques per a aquest codi. 


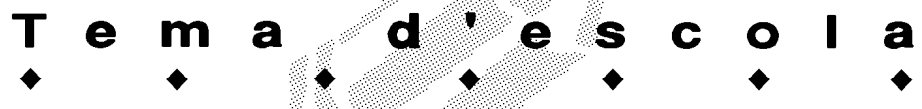

AnÀlisi dels Resultats

En aquest ítem les respostes correctes donades pel conjunt dels alumnes universitaris ha estat aproximadament el doble que les dels d'ESO de Catalunya. Un altre cop, quan mirem la resposta errònia, els valors resulten excessivament alts: $34,5 \%$ a EM i $52,6 \%$ a EP.

Algunes de les respostes errònies resulten curioses, perquè hi ha diversos alumnes que afirmen que, per a ells, el diari que més probablement doni una millor predicció del suport al president és el 4 , perquè "la gent que hi ha telefonat ho ha fet voluntàriament", o "no es pot controlar a qui truca", o "si hi han trucat es tracta de gent conscienciada", o "mostren un rebuig patètic al president ja que "al diari 4 una mateixa persona hi pot trucar diversos cops", o "els qui hi truquen poden estar afiliats al mateix partit". També hi ha qui deu ser un especialista en això del càlcul de probabilitats: "Ho he calculat. Té més vots el 3"; qui selecciona el diari 2 a partir d'un concepte de "més gran" realment confús ("perquè el suport és el més gran: $39 \%$ "); qui tria els diaris 2 i 4 a partir d'uns dibuixos de fraccions (?), qui diu que és el 3 , ja que "39\% és el resultat mitjà de les quatre mostres dels diaris" i qui selecciona el diari 2, calculant el percentatge del diari així: "100 - 41\%=59\%".

\section{Preguntes 37 i 38. El millor cotxe}

Una revista de cotxes utilitza un sistema de puntuacions per avaluar els nous cotxes i concedeix el premi "El millor cotxe de l'any" al cotxe amb la puntuació total més alta. S'estan avaluant cinc cotxes nous. Les seves puntuacions es mostren a la taula següent:

$\begin{array}{ccccc} & \begin{array}{c}\text { Seguretat } \\ (S)\end{array} & \begin{array}{c}\text { Estalvi de } \\ \text { combustible } \\ (C)\end{array} & \begin{array}{c}\text { Disseny } \\ \text { exterior } \\ (D)\end{array} & \begin{array}{c}\text { Habitacle } \\ \text { interior } \\ \text { Cotxe }\end{array} \\ \text { Ca } & 3 & 1 & 2 & 3 \\ \text { M2 } & 2 & 2 & 2 & 2 \\ \text { Sp } & 3 & 1 & 3 & 2 \\ \text { N1 } & 1 & 3 & 3 & 3 \\ \text { XK } & 3 & 2 & 3 & 2\end{array}$

Les puntuacions s'interpreten de la manera següent: 3 punts (excel/lent), 2 punts (bo) i 1 punt (acceptable).

Pregunta 37.

Per calcular la puntuació total d'un cotxe, la revista utilitza la següent regla, que dóna una suma poderada de les puntuacions individuals:

Puntuació total $=(3 \times S)+C+D+H$

Calcula la puntuació total del cotxe "Ca". Escriu la teva resposta a l'espai: Puntuació total de "Ca": .........
Pregunta 38.

El fabricant del cotxe "Ca" va pensar que la regla per obtenir la puntuació total no era justa.

Escriu una regla per calcular la puntuació total de forma que el cotxe "Ca" sigui el guanyador.

La teva regla ha d'incloure les quatre variables $i$ has d'escriure la regla reomplint amb nombres positius els quatre espais de l'equació següent:

Puntuació total $=\ldots \times S+\ldots \times C+\ldots \times D+\ldots \times H$

Valoració de la Pregunta 37

Segons el criteri de puntuació indicat al PISA, es dóna la màxima puntuació (codi 1) quan es respon: "15 punts". No es dóna cap puntuació quan han donat altres respostes (codi 0) o bé quan no s'ha contestat (codi 9).

Els resultats obtinguts pels alumnes de Magisteri al realitzar la tasca de la pregunta 37 es comptabilitzen a la taula 7.

\begin{tabular}{lccc}
\multicolumn{5}{c}{ RESPOSTA PREGUNTA 37 (En \%) } \\
Codi 1 & Codi 0 & Codi 9 \\
OCDE & 72,9 & - & - \\
ESP & 71,4 & - & - \\
CAT & 70,9 & - & - \\
EF & $\mathbf{9 4 , 9}$ & $\mathbf{5 , 1}$ & $\mathbf{0}$ \\
EM & $\mathbf{9 6 , 6}$ & $\mathbf{3 , 4}$ & $\mathbf{0}$ \\
EP & $\mathbf{8 1 , 6}$ & $\mathbf{1 0 , 5}$ & $\mathbf{7 , 9}$ \\
LE & $\mathbf{8 8 , 5}$ & $\mathbf{1 1 , 5}$ & $\mathbf{0}$ \\
MAG & $\mathbf{9 0 , 2}$ & $\mathbf{7 , 6}$ & $\mathbf{2 , 2}$
\end{tabular}

Taula 7. Percentatge de resposta obtinguda a la pregunta 37 (EI millor cotxe). El guió (-) indica que no es disposa de dades numèriques per a aquest codi.

AnÀlisi dels Resultats

Els resultats per a aquesta tasca són els millors de tota la prova, ja que són del $90,2 \%$ si es comptabilitza el total dels alumnes de Magisteri. Per especialitats, sobta una mica el 10,5\% de resposta errònia a EP i l' $11,5 \%$ a $E M$, atès el baix nivell de dificultat de la pregunta (Nivell 2. Reproducció i procediments rutinaris).

Valoració de la Pregunta 38

El criteri indicat al PISA atorga la màxima puntuació (codi 1) si s'escriu una regla correcta que converteixi el cotxe "Ca" en guanyador. Per contra, quan això no succeeixi (codi 0 ) o no s'hagi contestat (codi 9), no es donarà cap puntuació.

Els resultats obtinguts pels alumnes de Magisteri (en percentatge) al realitzar la tasca de la pregunta 38 es comptabilitzen a la taula 8.

AnÀlisi dels Resultats

Com que la tasca a realitzar en aquesta pregunta és de nivell 5 , els resultats globals són semblants als obtinguts a l'altra pregunta del mateix nivell de dificultat, la 


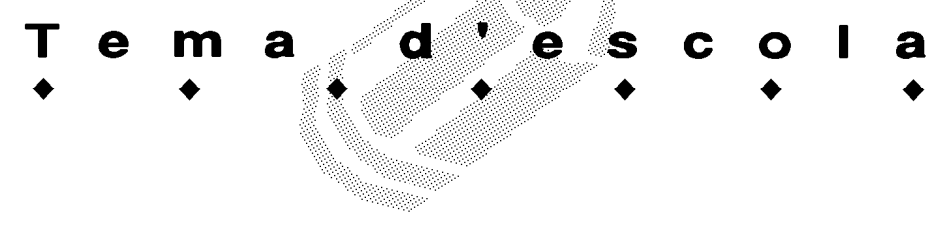

36. A EF i a EM la resposta errònia és bastant alta: $23,1 \%$ i $24,1 \%$, respectivament. És a dir, un de cada quatre estudiants ho resol malament. A les altres dues especialitats la situació empitjora força, ja que a LE se situa en el $42,3 \%$ i a EP puja fins al 55,3\%.

\begin{tabular}{lccc}
\multicolumn{4}{c}{ RESPOSTA PREGUNTA 38 (En \%) } \\
OCDE & Codi 1 & Codi 0 & Codi 9 \\
ESP & 25,4 & - & - \\
CAT & 22,2 & - & - \\
EF & 22,5 & - & - \\
EM & 71,8 & $\mathbf{2 3 , 1}$ & $\mathbf{5 , 1}$ \\
EP & $\mathbf{7 2 , 4}$ & $\mathbf{2 4 , 1}$ & $\mathbf{3 , 5}$ \\
LE & $\mathbf{3 1 , 6}$ & $\mathbf{5 5 , 3}$ & $\mathbf{1 3 , 1}$ \\
MAG & $\mathbf{4 6 , 2}$ & $\mathbf{4 2 , 3}$ & $\mathbf{1 1 , 5}$ \\
& 55,3 & $\mathbf{3 6 , 4}$ & $\mathbf{8 , 3}$
\end{tabular}

Taula 8. Percentatge de resposta obtinguda a la pregunta 38 (EI millor cotxe). El guió (-) indica que no es disposa de dades numèriques per a aquest codi.

Dels qui donen una resposta correcta, hi ha hagut qui ha necessitat uns números realment elevats per convertir el cotxe "Ca" en guanyador:

$30 \times \mathrm{S}+5 \mathrm{xC}+10 \times \mathrm{D}+30 \mathrm{xH}$.

Entre les respostes equivocades n'hi ha per a tots els gustos. Des de qui fa servir coeficients nuls per escriure la fórmula $(0 \times S+0 \times C+0 \times D+3 \times H)$ a qui selecciona una combinació de números que converteixen "Ca" en un colíder que ha de compartir el primer Iloc $(5,2,1,3)$, passant pels qui el deixen en penúltima posició $(5,4,6,5)$, i fins i tot en l'última $(3,3,3,3)$ !

\section{Recapitulació}

Els nostres estudiants de Magisteri procedeixen majoritàriament de Catalunya, tot i que malgrat estar en el primer quadrimestre del primer curs de Magisteri, no tots provenen directament del batxillerat, ja que hi ha una entrada des dels cicles formatius i també hi ha un percentatge d'alumnes provinents d'altres estudis (la majoria sense completar). A la taula 9 es comparen els percentatges d'èxit en cada qüestió entre els resultats dels nostres alumnes i els generals a Catalunya. Recordem que corresponen a "tots" els estudiants de 4t nivell d'ESO.

Excepte en la pregunta 10 -establir trams horaris per poder xatejar entre Sidney i Berlin-que millora molt poc; i en la pregunta 37 -valorar el millor cotxe-, que ja donava resultats encertats relativament alts a l'acabar l'ESO, s'observen al voltant del doble de respostes correctes a $1 r$ curs de Magisteri que als 14 anys. No obstant això, pensant que aquest alumnat s'ha de convertir en relativament poc temps en mestre-guia de raonaments matemàtics bàsics, ens sembla preocupant que, exceptuant la qüestió 37 , hi hagi en totes les altres una mitjana d'error del $45 \%$.

Si la comunitat educativa, en general, i la universitat en particular, el que vol és la millora de la formació bàsica dels futurs ciutadans, no hauria d'ignorar aquesta situació.

\section{Referències bibliogràfiques}

OCDE. The PISA 2003 Assessment Framework. Mathematics, Reading, Science and Problem Solving Knowledge and Skills. Edit. OCDE. París. 2003.

OCDE. Organisation for Economic Co-operation and Development. 2005 (a). www.ocde.org/home

OCDE. Informe PISA2003. Aprender para el mundo de mañana. Edit. Santillana. Madrid. 2005 (b).

PISA 2003. Pruebas de Matemáticas y de Solución de Problemas. Instituto Nacional de Evaluación y Calidad del Sistema Educativo (INECSE). Ministerio de Educación y Ciencia. Madrid. 2005. www.ince.mec.es

$\begin{array}{lccccccc}\text { Pregunta } & 1 & 2 & 9 & 10 & 36 & 37 & 38 \\ \text { 15 anys Catalunya } & 33,9 & 12,0 & 47,1 & 22,4 & 30,6 & 70,9 & 22,5 \\ \text { 1r Magisteri } & 74,2 & 22,0 & 72,0 & 27,3 & 64,4 & 90,2 & 55,3\end{array}$

Taula 9. Comparació dels percentatges d'èxit obtinguts pels alumnes de 4t d'ESO de Catalunya amb els de l'ensenyament de Mestres.

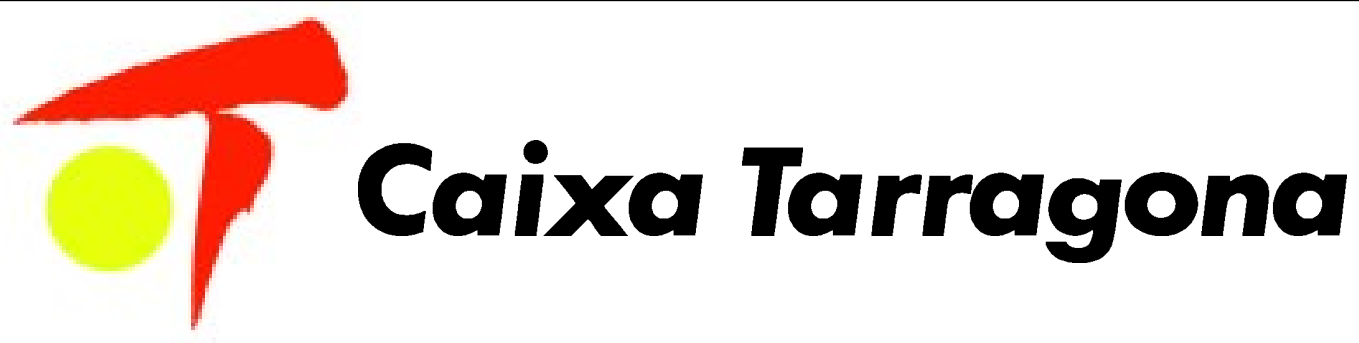

